\title{
Investigation and Thoughts on Cultivating College Students' Leadership under the Mode of "ShuangWei" Practice Quality Education
}

\author{
Yingmei Peng \\ Psychological Counseling Center \\ Jiangxi University of Traditional Chinese Medicine \\ Nanchang City, China \\ Zhibin Zhong * \\ Psychological Counseling Center \\ Jiangxi University of Traditional Chinese Medicine \\ Nanchang City, China
}

\author{
Xingyu Ding \\ College of Graduate \\ Jiangxi University of Traditional Chinese Medicine \\ Nanchang City, China \\ Yunfeng Liu \\ Office of Student Affairs \\ Jiangxi University of Traditional Chinese Medicine \\ Nanchang City, China
}

\begin{abstract}
In this study, 202 students from Jiangxi University of Traditional Chinese Medicine were selected as subjects. The subjects were divided into two groups: the Shuangwei group and the non-Shuangwei group. A one-year follow-up survey was conducted on their leadership level. The results showed that: (1) After intervention of Shuangwei practice mode, the leadership level of Shuangwei group was significantly higher than the nonShuangwei one; (2) There was no significant difference in the leadership level of the non-Shuangwei group before and after the intervention; (3) The social responsibility leadership scores and leadership practice behavior scores of the Shuangwei group were significantly higher than those of the non-Shuangwei one, but there was no significant difference between the two groups in the scores of emotional intelligence leadership. Conclusion: This study puts forward some thoughts on the cultivation of college students' leadership, that is, to cultivate the college students with great social responsibility as the starting point, and to develop the leadership training goal for all college students as well as to pay attention to students' emotional intelligence improvement in the cultivation process.
\end{abstract}

Keywords-college student; leadership; cultivating; Shuangwei practice mode; quality education

\section{INTRODUCTION}

The word "leadership" has the meaning of leading and guiding as a daily term, and as a technical term, its definition is different. At present, there is no unified definition of leadership in academic circles, but it is combined with many literatures (e.g. Huo Guoqing et al., 2008; Du Haikun, 2014; Zhou Dan, 2019) [1-3], leadership can be considered as a capability and quality that leaders demonstrate in organizing, directing, and leading teams to achieve common organizational goals. In addition, American scholars Chapman and O'neil (2004) argue that leadership is more than just the ability of leaders. Leadership logically also includes the ability of someone who be leaded. In a sense, leadership is the leader. The attraction and influence of the interaction with the choice and reaction of

Project supported by the subject of Research on College Students' Leadership Training under the Double-Education Mode (2018jzzd-1)

Corresponding author: Zhong Zhibin, 494234679@qq.com the leader [4]. In summary, college student's leadership refers to the comprehensive qualities and abilities that individual students need to perform in the leadership or non-leadership roles and processes.

At present, there is a lack of consensus training programs for college students' leadership training, and the only programs are not universal which are focus more on the student cadres and the average students are less involved. The Shuangwei practice class is a new mode of quality education in Chinese colleges and universities which is based on school motto "upholding learning and virtue, striving for strength and perfection", and combined with experience of running school for 60 years by Jiangxi University of Traditional Chinese Medicine [5]. The class focuses on cultivating students' basic qualities such as willpower, dedication, learning ability and thinking ability. It explores an extracurricular quality education mode that does not set a threshold, is open to all students, aims to promote students' all-round development, and effectively improves students' comprehensive quality. Therefore, this study is based on the students of the Shuangwei practice classes. It is hoped that by comparing the changes in leadership levels of 202 participants (including those who have joined and not joined the practice class) from 2017 (before intervention) to 2018 (after intervention), and to draws certain conclusions as well as provides a theoretical basis and a preferred solution for the university to cultivate "socialist builders and successors" with excellent leadership qualities.

\section{Research Methods}

This study used a convenient sampling method to issue questionnaires from 2017 to 2018. The questionnaires were based on real-name systems. After eliminate the questionnaires that were not fully involved in the whole process, a total of 404 valid questionnaires were collected, that is, the number of effective participants was 202. The subjects were divided into two groups: the Shuangwei group and the non-Shuangwei group. The leadership level was measured using the Chinese 
University Leadership Development Assessment Scale [6] compiled by Dr. Tao Siliang in 2014. This scale total has 122 questions and includes 3 subscales, which are EIL (Emotionally Intelligent Leadership for Students Inventory), SRL (The socially Responsible Leadership Scale), LPI (The Student Leadership Practices Inventory), higher the total score, the higher the level of leadership. In this study, the Cronach's $\alpha$ coefficient of the scale was 0.975 that stands for a high degree of reliability.

\section{RESEARCH RESULTS}

A. The change of leadership level of two groups of college students before and after the intervention of Shuangwei practice mode

Independent sample t test was performed on the leadership levels of the two groups before and after the intervention. The results are shown in Table I: The Shuangwei group subjects had a significant improvement in leadership level ( $t=4.74$, $\mathrm{p}<0.001)$ after a one-year intervention $(\mathrm{t}=4.74, \mathrm{p}<0.001)$. There was no significant difference in the level of leadership on the non-Shuangwei group compared with the time of enrollment ( $>0.05)$. That is to say, the Shuangwei practice mode could improve levels of university students' leadership efficiently.

In order to prove that the two groups of subjects are at a same leadership level before the intervention begins, an independent sample t-test was performed on the questionnaires answered by the two groups in 2017. It can be seen from the above table that there is no significant difference in the leadership level between the Shuangwei group and the nonShuangwei group before intervention $(p>0.05)$. And then the leadership level of the two groups after one year of intervention was compared. The results showed that the leadership level of the Shuangwei group was significantly higher than that of the non-Shuangwei group $(t=2.03, p<0.05)$. It also means that the improvement of the leadership level of the Shuangwei group is partly due to the training of the Shuangwei practice mode.

\section{B. Specific differences between the two groups after the intervention}

However, it is not clear from the total score that the leadership level of the Shuangwei group in which aspect is better than the non-Shuangwei group. In this study, therefore, the scores of the two subscales and their dimensions were compared between the two groups. The results are shown in Table II. The SRL scores $(t=2.37, p<0.05)$ and the LPI scores $(t=2.13, p<0.05)$ of the Shuangwei group were significantly higher than those of the non-Shuangwei group. There was no significant difference in the scores of EIL and its dimensions between the two groups ( $p>0.05)$. To a certain extent, this can explain the Shuangwei practice mode of promoting the role of college students in socially responsible leadership and college students' leadership behavior.
TABLE I. DIFFERENCES IN LEADERSHIP LEVELS BETWEEN SUBJECTS IN THE SHUANGWEI GROUP AND THE NON-SHUANGWEI GROUP SUBJECTS BEFORE AND AFTER INTERVENTION $(\mathrm{M} \pm \mathrm{SD})$

\begin{tabular}{|c|c|c|c|}
\hline \multirow{2}{*}{ Group } & \multicolumn{2}{|c|}{ Intervention state } & \multirow{2}{*}{$t$} \\
\hline & before & after & \\
\hline $\begin{array}{c}\text { Shuangwei } \\
\text { group }(n=152)\end{array}$ & $441.14 \pm 42.67$ & $465.02 \pm 45.08$ & $4.74^{* * *}$ \\
\hline $\begin{array}{l}\text { Non-Shuangwei } \\
\text { group }(n=50)\end{array}$ & $442.57 \pm 37.21$ & $445.14 \pm 64.32$ & -0.25 \\
\hline$t$ & -0.21 & $2.03^{*}$ & \\
\hline
\end{tabular}

\section{THOUGHTS ABOUT CULTIVATION OF UNIVERSITY STUDENTS’ LEADERSHIP IN THE NEW ERA}

\section{A. To cultivate university students of new era who have grate social responsibility.}

Chairman Xi Jinping stated at the National Education Conference in 2018 that our education must take the cultivation of socialist builders and successors as the fundamental task. The socialist builders and successors have the same point and difference. The successor must be the builder, and the builder may not be a good successor. According to Table II, although there are significant differences in the total scores of the two groups of students on the SRL, there are no significant differences in the dimensions of "citizenship" and "change". Therefore, cultivating college students with great social responsibility still has a long way to go. Only when the heart is filled with firm beliefs and ambitions for social construction and national prosperity, can it become a socialist successor. At the same time, it also requires that colleges and universities do not make superficial efforts and pay attention to actual results when promoting students' leadership education

\section{B. Target the educational goal of leadership at every student}

China's leadership education began in the 1990s, with a few 985 colleges and universities taking the lead, and it has been nearly 30 years since today. Although the research on leadership in China is gradually deepening, the general public lacks the awareness of leadership training. Although the number of universities implementing leadership education has increased, leadership education still remains in elite students (such as student leaders and Comunist Party members). In February 2017, Xi Jinping put forward the work requirements of "achieving all employees, educating people in all processes and educating people in all directions" in the Opinions on Strengthening and Improving the Ideological and Political Work in Colleges and Universities under the New Situation. It aims to build a platform for many ordinary students who are not excellent by simply submitting their application to join the Shuangwei team. The above research results further prove the effectiveness of the Shuangwei practice mode in intervening college students' leadership and provide a reference for college leadership education. Hence, it is imperative to target the goal of leadership education to more college students. 
TABLE II. DIFFERENCES BETWEEN THE SCORES OF THE THREE SUBSCALES AND THEIR DIMENSIONS IN THE TWO GROUPS AFTER THE INTERVENTION OF THE DOUBLE-ONLY PRACTICE MODE

\begin{tabular}{|c|c|c|c|}
\hline & Shuangwei Group(M $\pm \mathrm{SD})$ & Non-Shuangwei Group (M \pm SD) & $t$ \\
\hline EIL (Total Scores) & $91.99 \pm 11.76$ & $87.44 \pm 17.54$ & 1.71 \\
\hline Consciousness of Context & $28.28 \pm 4.56$ & $26.72 \pm 6.39$ & 1.59 \\
\hline Consciousness of Self & $32.22 \pm 3.69$ & $30.74 \pm 5.65$ & 1.74 \\
\hline Consciousness of Others & $31.49 \pm 4.29$ & $29.98 \pm 6.28$ & 1.58 \\
\hline SRL (Total Scores) & $255.71 \pm 21.63$ & $246.42 \pm 30.30$ & $2.37^{*}$ \\
\hline Consciousness of Self & $30.89 \pm 3.45$ & $30.76 \pm 3.85$ & 0.23 \\
\hline Congruence & $27.43 \pm 3.08$ & $26.06 \pm 3.69$ & $2.61^{*}$ \\
\hline Commitment & $24.47 \pm 2.55$ & $23.26 \pm 3.39$ & $2.70^{* *}$ \\
\hline Common Purpose & $32.68 \pm 3.21$ & $31.14 \pm 4.55$ & $2.23^{*}$ \\
\hline Controversy with Civility & $41.38 \pm 3.61$ & $39.82 \pm 4.69$ & $2.44^{*}$ \\
\hline Citizenship & $32.41 \pm 3.48$ & $31.42 \pm 4.59$ & 1.61 \\
\hline Change & $34.98 \pm 3.63$ & $34.04 \pm 4.50$ & 1.49 \\
\hline LPI (Total Scores) & $117.32 \pm 15.92$ & $111.28 \pm 21.21$ & $2.13^{*}$ \\
\hline Model the way & $23.72 \pm 3.27$ & $22.22 \pm 3.96$ & $2.67^{* *}$ \\
\hline Inspired a shared vision & $23.21 \pm 3.67$ & $22.38 \pm 4.91$ & 1.27 \\
\hline Challenge the process & $22.74 \pm 3.75$ & $21.24 \pm 4.55$ & $2.32^{*}$ \\
\hline Encourage the heart & $23.74 \pm 3.41$ & $22.62 \pm 4.78$ & 1.54 \\
\hline
\end{tabular}

stands for $p<0.01$

\section{Thinking highly of the improvement of college students' emotional intelligence}

Through the measurement of leadership level after intervention in the Shuangwei group and non-Shuangwei groups, the study found that there was no significant difference in the scores of the EIL and its dimensions. This result indicates that the current Shuangwei practice mode does not effectively interfere with students' emotional intelligence leadership. Emotional intelligence leadership is an organic combination of emotional intelligence and leadership. Its core is emotional intelligence. As an important psychological quality, it has a significant role in the study and career of college students. Therefore, in future research and practice, attention should be paid to make up for this deficiency. For example, universities and colleges can do something to improve students' emotional intelligence, such as:

\section{Strengthening the frustration education for students}

According to the theory of Israel psychologist Bar-On (1997) [7], emotional intelligence refers to the sum of a series of emotional, personal and interpersonal abilities that can influence an individual's response to environmental needs and stress dilemmas. Frustration education can enable students to have a literate literacy and face difficulties in a usual mind. In the process of frustration education, colleges and universities not only provide theoretical counseling through traditional lectures and posters, but also provide psychological counseling for frustrated students. They should also set up frustration education elective courses, and carry out frustration simulation activities in the classroom to enhance students' ability to resist setbacks.

\section{E. Establishing students' sufficient self-efficacy}

Self-efficacy refers to the individual's judgment and belief about whether or not he has certain abilities. High self-efficacy allows students to have full confidence in the face of challenges, and is a necessary prerequisite for individuals to recover their self-confidence more quickly when they are frustrated. In addition to teaching theoretical knowledge, the school can also help students strengthen self-awareness, discover self-worth and build self-confidence in practice by organizing group counseling activities for self-efficacy.

\section{SUMMARY}

With the progress of the times, we began to become more focused on the comprehensive quality of talents, and leadership is a very important part of it. Through the investigation, we found that under the intervention of the Shuangwei-practice quality education model, the leadership levels of students have been improved. And further analysis of the data shows that the current model needs to be improved that our education should pay more attention to improving the emotional intelligence of college students in the future. In addition, this study only selected Dr. Tao Siliang's leadership questionnaire as a measurement tool. This survey did not study the practical effects of the dual-mode model under other leadership theories. Therefore, in the future research, the level of leadership of university students in other dimensions will be further tested, and the existing Shuangwei practice mode will be further improved according the survey data.

\section{REFERENCES}

[1] Huo Guoqin, Meng Jianping, Liu sifeng. Information Resources Management [J].Management Review, 2008(04):31-38+24+64

[2] Du Haikun. Research of American Citizenship Education Curriculum Models. [D].China University of Geosciences, 2014.

[3] Zhou Dan. Research on College Students' Leadership Cultivation under the Background of "Double Creation" [D]. Xi'An University of Technology, 2019.

[4] (In Chinese) Research Group of "Science and Technology Leadership Research" of the Chinese Academy of Sciences, Miao Jianming, Huo Guoqing. Leadership Five Forces Model Research. [J]. Leadership Science, 2006(09):20-23. 


\section{PRESS}

[5] (In Chinese) Yu Dajun, Luo Xiaoliang, Zhang Hanying. Reflections on the Cultivation of College Students' Leadership under the Shuangwei Mode. [J]. LAOQUJIANSHE, 2015(06): 52-54.
[6] Tao Siliang. Research on Leadership Development and Education Model for Chinese College Students [D]. East China Normal University, 2014.

[7] Reuven Bar-On. Emotional Quotient Inventory: Technical Manual [M].Toronto: Multi- Health Systems Ins.1997. 